\title{
Understanding the drying shrinkage performance of alkali-activated slag mortars
}

\author{
Hailong Ye*, Christopher Cartwright, Farshad Rajabipour, Aleksandra Radlińska \\ Department of Civil and Environmental Engineering, The Pennsylvania State University, 3127 \\ Research Drive, State College, PA, 16801 \\ * Corresponding author, Phone: 1-484-260-4003, Email: huy131@psu.edu Fax: +1 814-
}

863-7304

\begin{abstract}
In this work, drying shrinkage of four alkali-activated slag (AAS) mortars, prepared using various types/dosages of activator, was characterized at four different levels of relative humidity $(\mathrm{RH})$ and two drying regimes (i.e. direct and step-wise drying). The results show that drying shrinkage values of AAS are significantly dependent on the drying rate, as AAS shrinks more when the RH is decreased gradually instead of directly. At high RH, the drying shrinkage of AAS exhibits a considerable visco-elastic/visco-plastic behavior, in comparison to ordinary portland cement (OPC). It is concluded that the cause of high-magnitude shrinkage in AAS mortar is due to the high visco-elastic/visco-plastic compliance (low creep modulus) of its solid skeleton. Furthermore, the activator affects the shrinkage behaviors of AAS by influencing the pore structure and mechanical properties.
\end{abstract}

Keywords: Alkali-activated slag; Relative humidity; Drying shrinkage; Shrinkage mechanism; Creep modulus

\section{Introduction}

Ground granulated blast-furnace slag is an amorphous by-product of iron industry. Research has shown that blast-furnace slag can be alkaline activated to potentially substitute the ordinary Portland cement (OPC) as an alternative binder in concrete [1,2]. Alkali activation of slag is the process of promoting the dissolution of aluminosilicate vitreous structures in slag in a high $\mathrm{pH}$ environment. The dissolved ionic species, including aluminates, silicates, calcium, and alkali ions, can then form various types of amorphous phases, including calcium-silicate-hydrate (C-S$\mathrm{H})$, calcium-aluminosilicate-hydrate $(\mathrm{C}-\mathrm{A}-\mathrm{S}-\mathrm{H})$, and alkali-aluminosilicate-hydrate $(\mathrm{N}-\mathrm{A}-\mathrm{S}-\mathrm{H})$, which provide the binding capabilities in concrete [3-5].

Alkali-activated slag (AAS) concrete can potentially offer high compressive strength and excellent performance against fire and chemical (acid, sulfate) attack [2, 6]. Recent environmental life-cycle assessment studies show that AAS concrete provide $25-50 \%$ reductions in $\mathrm{CO}_{2}$ emission and more than $40 \%$ reductions in embodied energy relative to OPC concrete [1, $7,8]$. Despite their favorable performance, the marketability and acceptance of AAS concretes in the industry have been hindered partly due to concerns related to their long-term durability [2], such as extensive shrinkage and micro-cracking [9, 10], rapid carbonation [11], and potential 
alkali-aggregate reaction [6]. Perhaps one of the most significant conundrums impeding the implementation of AAS concrete is their volumetric instability.

Many researchers have reported that AAS has a significantly higher drying shrinkage than OPC $[9,10,12-14]$, and investigated the shrinkage characteristics of AAS as a function of activator type/dosage [13, 15], curing conditions [16, 17], and aggregate properties [18, 19]. For instance, it was reported that the increased silicate content and dosage of activator can potentially increase the shrinkage of AAS [13, 15]. However, the scientific reasoning and mechanisms of the extensive large shrinkage in AAS have not yet been comprehensively understood. Instead, many researchers attributed the large shrinkage of AAS merely to its refined pore structure, as a high capillary force builds in the materials with a refined pore structure $[12,13]$. There is no doubt that the difference of pore structure between AAS and OPC can considerably affect the shrinkage behaviors. Nevertheless, previous investigation ignores the potential intrinsic difference between the main hydration products of AAS and OPC in term of shrinkage responses.

On the other hand, previous experiments mainly characterized the drying shrinkage of AAS at merely $50 \%$ relative humidity $(\mathrm{RH})$ atmosphere. Former studies have shown that AAS is likely vulnerable to carbonation [20], which may cause decalcification shrinkage of C-A-S-H during the tests. To eliminate the potential influence of carbon dioxide in the atmosphere, the drying shrinkage of AAS should be measured in an inert gaseous condition. Furthermore, the data about drying shrinkage of AAS over a broad range of $\mathrm{RH}$ is limited. Characterizing the shrinkage of AAS at various RH is important since it is generally believed that different shrinkage mechanisms may dominate at different $\mathrm{RH}$ ranges and over various sizes of pores [21]. A comprehensive characterization of the shrinkage can contribute to an in-depth understanding of the properties of AAS and guide developing the shrinkage mitigating strategies, which can improve the long-term durability of AAS concrete. The aforementioned knowledge gap needs to be bridged before AAS concrete can become a marketable and viable alternative to the energy intensive OPC concrete.

The main objectives of this research are to understand the shrinkage mechanism of AAS, and to illuminate the intrinsic reasons that are responsible for its large shrinkage and volumetric instability of AAS. In this paper, the shrinkage performance of four AAS mortars under various drying conditions was investigated, Furthermore, the influence of activator type/dosage, carbonation, pore structure on the shrinkage performance of AAS was elaborated.

\section{Experimental programs}

\subsection{Materials}

Grade 120 ground granulated blast-furnace slag with a density of $2.89 \mathrm{~g} / \mathrm{cm}^{3}$ and Type I portland cement with a density of $3.14 \mathrm{~g} / \mathrm{cm}^{3}$ were used in this study. The chemical compositions of slag and cement are shown in Table 1.

Table 1 Chemical compositions (by mass \%) of slag and portland cement

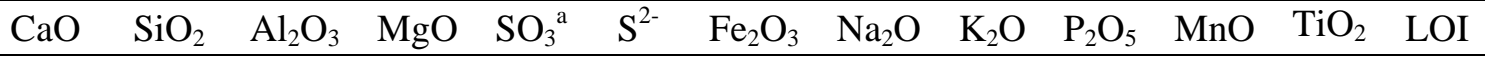




\begin{tabular}{cccccccccccccc} 
Slag & 43.83 & 30.04 & 12.74 & 4.79 & 3.11 & 0.85 & 1.16 & 0.24 & 0.40 & 0.08 & 0.22 & - & 2.56 \\
Cement & 62.5 & 19.9 & 5.44 & 2.31 & 4.93 & - & 2.26 & 0.30 & 0.89 & 0.23 & 0.09 & 0.29 & 0.86 \\
\hline
\end{tabular}

Note: a: The element compositions of slag were measured by ICP-AES method, the relatively high $\mathrm{SO}_{3}$ content in this slag is primarily due to the presence of gypsum. The composition of cement was provided by the supplier.

The mixture proportions of four AAS mortars and a control OPC mortar are listed in Table 2. All five mixtures were designed to have a constant volume-based liquid (water + activator) to solid (slag or cement) ratio. Because of the difference in density between slag and cement, as well as among various type/dosage of activator, the mass-based liquid-to-solid ratio varies from 0.489 to 0.510 for AAS. For OPC mixture, the mass-based water-to-cement ratio is 0.41 . In addition, a natural river sand with a fineness modulus 2.60 , oven dry specific gravity 2.52 , and absorption capacity $2.02 \%$ was used.

Mortars AAS1 and AAS2 were activated by a combination of sodium hydroxide $(\mathrm{NaOH})$ solution and aqueous sodium silicate (water glass) solution with different values of modulus $n$ $\left(n=\mathrm{SiO}_{2} / \mathrm{Na}_{2} \mathrm{O}\right)$ in activator. Mortars AAS3 and AAS4 were activated by $2 \mathrm{M}$ and $4 \mathrm{M} \mathrm{NaOH}$ solution, respectively. The $\mathrm{pH}$, modulus, and density of activators are listed in Table 2 .

Table 2. Mortar mixture proportions (per liter of mortar) and properties

\begin{tabular}{|c|c|c|c|c|c|}
\hline Parameters & AAS1 & AAS2 & AAS3 & AAS4 & OPC \\
\hline $\mathrm{NaOH}$ dry pellets $(\mathrm{g})$ & 23.8 & 5.9 & 23.7 & 47.5 & 0 \\
\hline Sodium silicate aqueous solution $^{\mathrm{c}}(\mathrm{g})$ & 35.7 & 95.5 & 0 & 0 & 0 \\
\hline Water $(\mathrm{g})^{\mathrm{a}}$ & 263.6 & 234.6 & 285.9 & 274.8 & 296.8 \\
\hline $\mathrm{n}\left(=\mathrm{SiO}_{2} / \mathrm{Na}_{2} \mathrm{O}\right.$ in activator $)$ (molar-based $)$ & 0.41 & 1.22 & 0 & 0 & 0 \\
\hline Initial $\mathrm{pH}$ of activator solution & 14.31 & 13.78 & 14.30 & 14.60 & $7.00^{\mathrm{b}}$ \\
\hline Density of activator $\left(\mathrm{g} / \mathrm{cm}^{3}\right)$ & 1.09 & 1.13 & 1.04 & 1.09 & $1.00^{\mathrm{b}}$ \\
\hline Cement $(\mathrm{g})$ & 0 & 0 & 0 & 0 & 656.6 \\
\hline Slag $(g)$ & 603.9 & 603.9 & 603.9 & 603.9 & 0 \\
\hline Sand (oven dried) (g) & 1247 & 1247 & 1247 & 1247 & 1247 \\
\hline Binder solution/solid (vol./vol.) & 1.30 & 1.30 & 1.30 & 1.30 & 1.30 \\
\hline Binder solution/solid (wt./wt.) & 0.49 & 0.51 & 0.47 & 0.49 & 0.41 \\
\hline Initial porosity $^{\mathrm{d}}$ & $56.5 \%$ & $56.5 \%$ & $56.5 \%$ & $56.5 \%$ & $56.5 \%$ \\
\hline 28-day compressive strength (MPa) & 28.0 & 46.4 & 23.5 & 41.7 & 40.0 \\
\hline
\end{tabular}

a: Water content includes absorption by oven dry sand.

b: They were not measured and assumed to be the same as pure water.

c: The aqueous sodium silicate solution contains $53.2 \%$ water, $28.8 \% \mathrm{SiO}_{2}$, and $18.0 \% \mathrm{Na}_{2} \mathrm{O}$ by mass (modulus $\left(\mathrm{n}=\mathrm{SiO}_{2} / \mathrm{Na}_{2} \mathrm{O}\right)$ is 1.60 and specific gravity is 1.60 at $20^{\circ} \mathrm{C}$ ).

$\mathrm{d}$ : It is the ratio of the volume of liquid (activator or water) to the total volume of liquid and solid (cement or slag). 


\subsection{Test Procedures}

\subsubsection{Mixing}

To prepare $\mathrm{NaOH}$ solution, reagent sodium hydroxide pellets were dissolved in distilled water at room temperature and sealed to prevent evaporation and carbonation. The aqueous sodium silicate solution was kept separately from $\mathrm{NaOH}$ solution. In order to dissolve the slag properly, $\mathrm{NaOH}$ solution was added first, followed by sodium silicate solutions after mixing for 15 minutes. The mixing was conducted in a Hobart mixer according to ASTM C305-12.

\subsubsection{Drying shrinkage and mass change}

A non-standardized mold with the dimensions of $12.7 \mathrm{~mm} \times 12.7 \mathrm{~mm} \times 139.7 \mathrm{~mm}$ was designed to cast "mini-bar" prism samples. Mini-bars (see Figure 1) were used to expedite drying shrinkage and allow samples to dry in Vena VC-10 environmental chambers. The chambers were capable of creating environments under various $\mathrm{RH}$ and/or gases (e.g., nitrogen purge). The PVC mold was able to be completely disassembled and had a gauge length of $101.6 \mathrm{~mm}$ (4 inches). The gauge studs used were one inch black oxide alloy steel cone point socket \#6-32 set screws. Length measurements were taken utilizing a modified digital comparator with an invar (low coefficient of thermal expansion) place holder and a measuring precision of 0.0001 inches. Simultaneous mass measurements were taken using a balance with a precision of $0.0001 \mathrm{~g}$ to determine the moisture loss upon drying. The samples were positioned on a grid panel in the chambers to enable uniform drying with minimal restrains.

Two regimes of drying were investigated in this study:

Direct drying: Environmental chambers were set at four different $\mathrm{RH}(85 \%, 70 \%, 50 \%$, and $30 \%)$ and constant temperature $\left(23 \pm 0.5^{\circ} \mathrm{C}\right)$. The drying shrinkage (direct drying) was measured for all five mixtures (four specimens per mixture) at each $\mathrm{RH}$ under dry nitrogen $\left(\mathrm{N}_{2}\right)$ purge after 7 days of moist curing $\left(100 \% \mathrm{RH}, 23 \pm 0.5{ }^{\circ} \mathrm{C}\right)$. The concentration of $\mathrm{CO}_{2}$ in environmental chambers was recorded with a portable $\mathrm{CO}_{2}$ analyzer as $0 \mathrm{ppm}$. The measurement continues until the samples reach equilibrium, defined as both the mass and length changes of less than $2.0 \%$ over one week period.

Step-wise drying: After 7 days of moist curing, the specimens were sequentially dried at $85 \%$, $70 \%, 50 \%$ and finally $30 \% \mathrm{RH}$ under dry $\mathrm{N}_{2}$ purge. The RH was dropped in each level when the samples reached equilibrium.

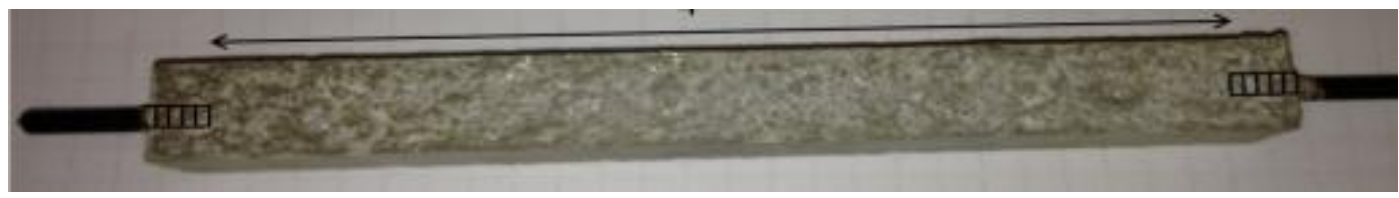

Figure 1 "Mini-bar" specimen for drying shrinkage measurements

\subsubsection{Elastic modulus}

Elastic modulus represents the resistance of materials against elastic deformation when a force (e.g. capillary pressure) is applied, which can affect the shrinkage magnitude. The elastic 
modulus of all five mixtures was measured according to ASTM C469, and the detailed procedure was previously reported by Cartwright et al. [10].

\subsubsection{Degree of saturation}

The degree of saturation is an important parameter related to shrinkage since it represents the fraction of water-filled pores which may contribute to the capillary forces. In order to calculate the degree of saturation of samples conditioned at various RH (i.e. 100\%, 85\%, 70\%, 50\%, and $30 \% \mathrm{RH}$ ), the total amount of porosity (volume of permeable pore space) and moisture content at various RH should be known. The total amount of porosity of each mortar mixture before drying (after 7 days moisture curing) was measured according to ASTM C642-13, and the detailed procedure was documented by Cartwright et al. [10]. The moisture content of samples can be calculated based on the mass data during drying (Section 2.2.2) and oven-dried at $105{ }^{\circ} \mathrm{C}$ until constant mass was achieved. Therefore, the degree of saturation can be calculated as the ratio of the volume of retained moisture to the volume of permeable pore space.

\subsubsection{Mercury intrusion porosimetry}

The mercury intrusion porosimetry (MIP) was implemented to characterize the pore structure (e.g. pore entry size distribution, porosity), as it is strongly related to the shrinkage. MIP is capable of measuring pore entry diameters ranging from 360 to $0.003 \mu \mathrm{m}$. All AAS and OPC paste samples were cast into $2 \mathrm{~mL}$ plastic vials, and moist cured for 7 days. At the end of moist curing, all samples were first vacuum dried at $50^{\circ} \mathrm{C}$ (to avoid an initially severe drying environment) for two days and then oven dried at $105^{\circ} \mathrm{C}$ until a constant mass was achieved. A duplicate of AAS2 was performed to test the repeatability of the MIP procedure.

\section{Results}

\subsection{Drying shrinkage and mass change}

\subsubsection{Direct drying}

Figure 2 shows the results of the measured (direct) drying shrinkage for all mortar mixtures. Except for AAS3 at 30\% RH, AAS mixtures show higher drying shrinkage than the control OPC mix at all RH. OPC shows increasing shrinkage with the decrease in $\mathrm{RH}$, which is consistent with previous findings $[22,23]$. However, the AAS mixtures show different drying behaviors than that of OPC. The largest ultimate drying shrinkage of mixtures AAS3 (1850 $\mu \varepsilon)$ and AAS4 $(1950 \mu \varepsilon)$ is observed at $70 \% \mathrm{RH}$; similarly, AAS1 $(2100 \mu \varepsilon)$ and AAS2 $(2275 \mu \varepsilon)$ shrink the most at $50 \% \mathrm{RH}$. This shrinkage characteristic of AAS mortars (the largest shrinkage deformations are not observed at the lowest $\mathrm{RH}$ ) differs significantly from that of OPC. The distinctive shrinkage performance of AAS will be explained in the Section 4.

Figure 3 presents the ultimate mass loss data of all mixtures conditioned at various $\mathrm{RH}$. The mass loss results of the AAS mixtures were greater than those of OPC mixture at any given RH. This contradicts the findings of Collins and Sanjayan [12] who measured lower mass loss upon drying for AAS than OPC. AAS3 showed the largest mass loss of all mixtures for all RH conditions, which is likely due to its coarsest pore structure among all AAS mixtures (will be elaborated in Section 3.4). 


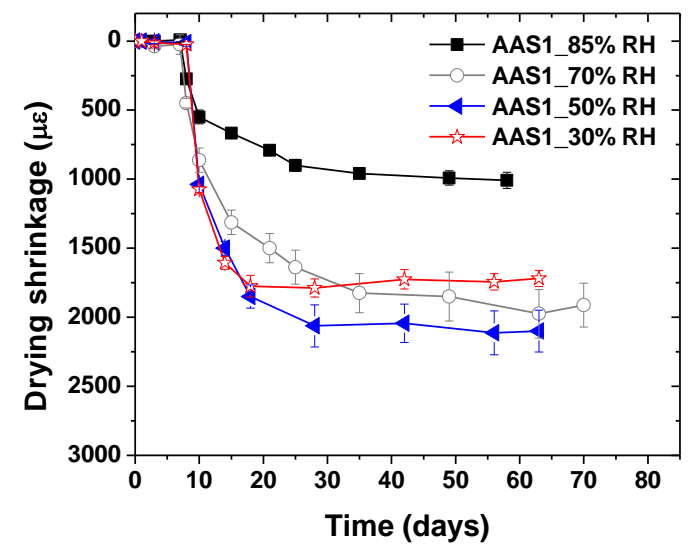

(a)

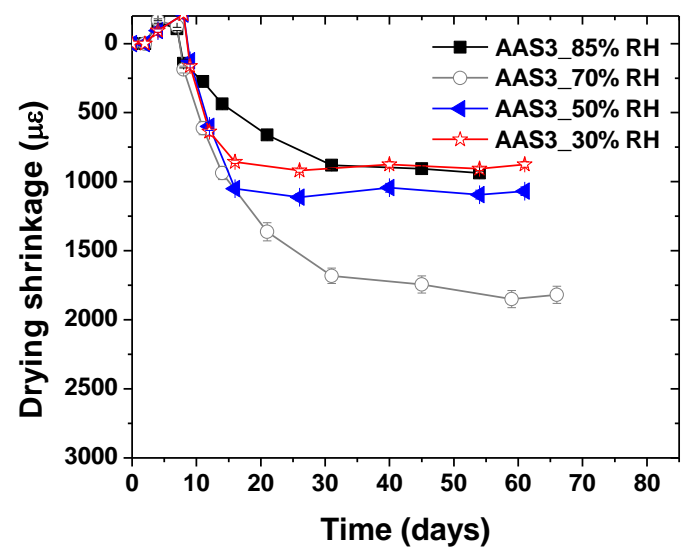

(c)

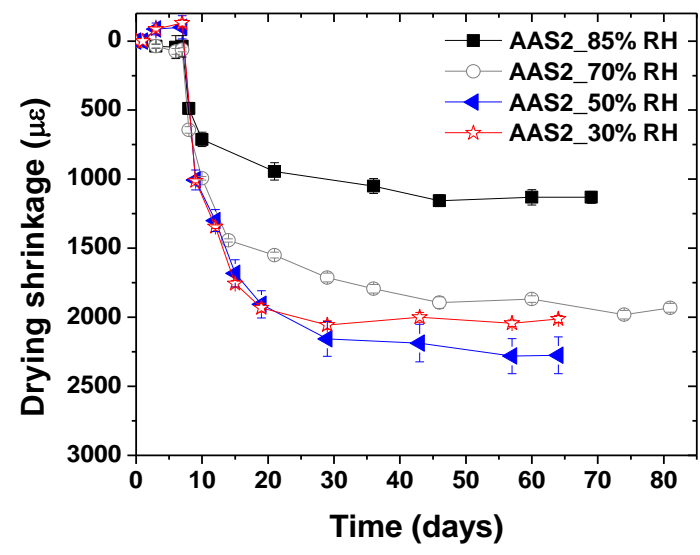

(b)

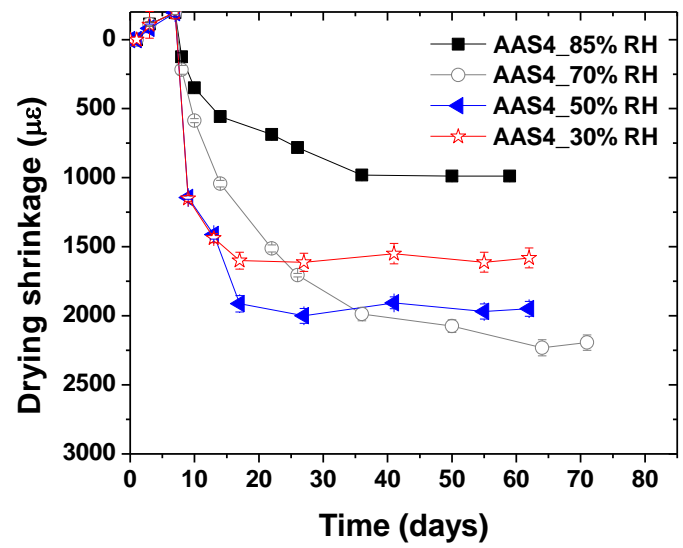

(d)

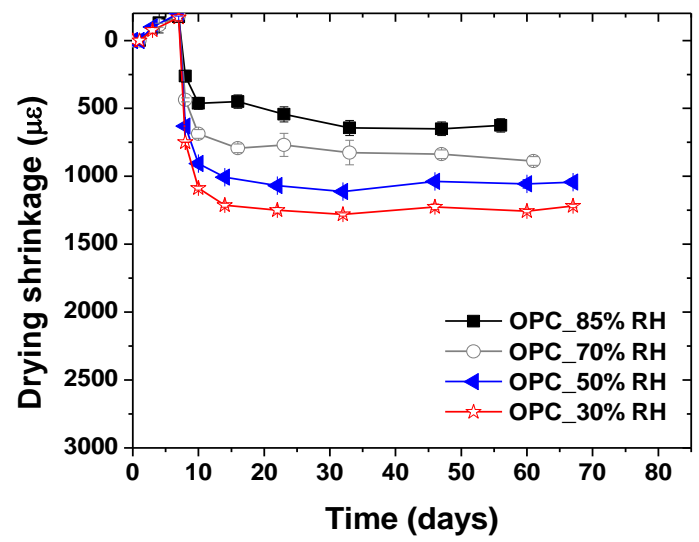

(e)

Figure 2 Drying shrinkage (direct drying) under nitrogen purge for all mortar mixtures (a) AAS1;

(b) AAS2; (c) AAS3; (d) AAS4; (e) OPC 


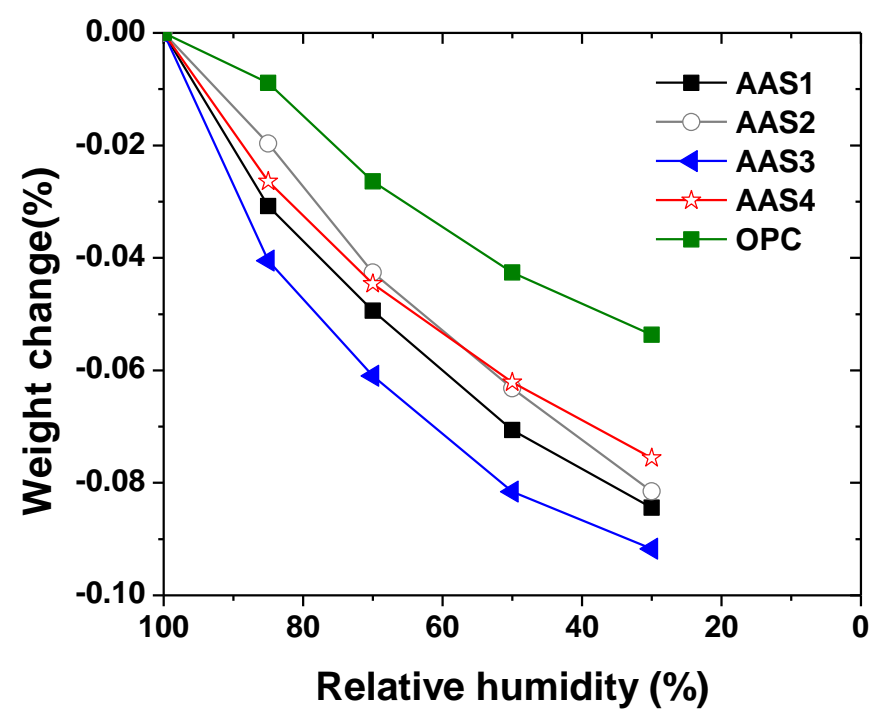

Figure 3 Correlation between $\mathrm{RH}$ and weight loss for all mortar mixtures

\subsubsection{Step-wise drying}

Figure 4 shows the results of the step-wise drying procedure used to evaluate all five mortar mixtures. Similar to direct drying, the control OPC showed the lowest drying shrinkage and mass loss compared to all AAS mixtures at any given RH. The AAS mortars activated solely by $\mathrm{NaOH}$ (i.e. AAS3 and AAS4) show slightly higher drying shrinkage compared to other AAS mixtures, though the differences between the four are marginal.

When dried gradually under the step-wise process, the relationship between shrinkage and RH for AAS materials differs significantly from direct drying. For example, when dried directly to $50 \% \mathrm{RH}, \mathrm{AAS} 3$ shows an ultimate shrinkage of $1050 \mu \varepsilon$; however, when dried gradually to $50 \%$ $\mathrm{RH}$, the same mixture shows $150 \%$ higher shrinkage deformations $(2650 \mu \varepsilon)$. Similar tendencies are observed for the other AAS mixtures. All mixtures lost slightly less mass during the stepwise drying compared to the direct drying process. Clearly, the drying shrinkage behavior of AAS materials is highly dependent on the drying rate and drying history. As further explained in the Section 4, this distinctive shrinkage performance of AAS is mainly attributed to the creep effects in AAS under the internal capillary stress at high RH. 


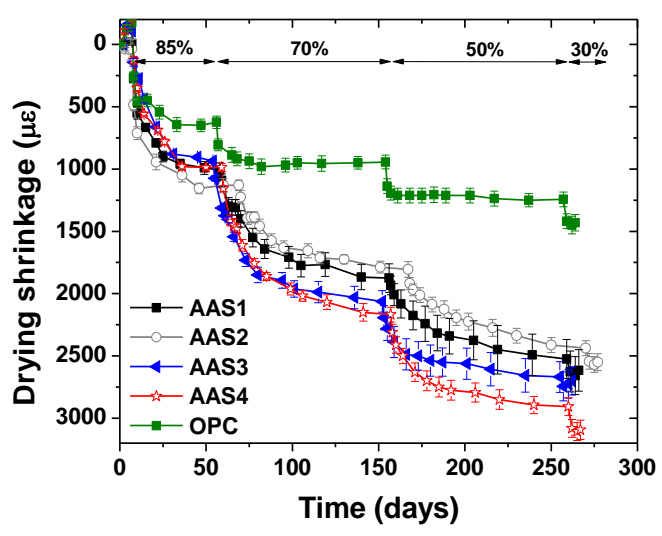

(a)

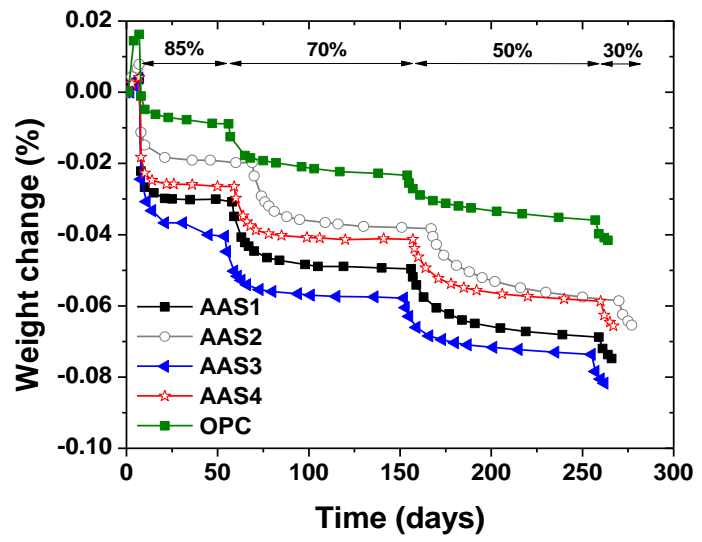

(b)

Figure 4 (a) Drying shrinkage and (b) weight change of mortar mixtures using the step-wise procedure (Considering that each mixture stops shrinking at different time, the segment of drying $\mathrm{RH}$ is merely for visional guidance)

\subsection{Elastic modulus}

Table 3 shows the values for 28-day static elastic modulus of all five mixtures. It shows that AAS3 and AAS4 have a smaller elastic modulus (approximately $13.5 \mathrm{GPa}$ ) than the other three mixtures (ranging from 19.49 to $20.71 \mathrm{GPa}$ ). AAS1, AAS2, and OPC show similar elastic modulus values at 28 days. Considering that the Poisson's ratio of AAS concrete as about 0.13 [24], which is slightly lower than that of OPC, it can be inferred that the bulk modulus of mortars AAS3 and AAS4 are more than 67\% smaller than those of the other three mortars.

Table 3. Modulus of elasticity of mortars at 28 days (each data point is the average of two replicates of cylindrical specimens)

\begin{tabular}{cc}
\hline Mix ID & Modulus of Elasticity $(\mathrm{GPa})$ \\
\hline AAS1 & 20.71 \\
AAS2 & 19.85 \\
AAS3 & 13.25 \\
AAS4 & 13.55 \\
OPC & 19.49 \\
\hline
\end{tabular}

\subsection{Degree of saturation}

Table 4 shows the degree of saturation for all five mixtures conditioned at various RH. All mortars show a slightly lower than $100 \%$ saturation at the end of the moist curing period (7 days). This may be attributed to self-desiccation in mortars, which could not be completely relieved by external moist curing. In addition, it can be seen that OPC has the highest degree of saturation among all 5 mixtures at any RH. It is also observed that AAS3 shows the lowest degree of saturation at any $\mathrm{RH}$, which may be attributed to its coarsest pore structure among all AAS mixtures (Section 3.4). 
Table 4. Ultimate degree of saturation (vol \%) of mortars conditioned at various RH

\begin{tabular}{cccccc}
\hline Mix ID & $100 \% \mathrm{RH}^{\mathrm{a}}$ & $85 \% \mathrm{RH}$ & $70 \% \mathrm{RH}$ & $50 \% \mathrm{RH}$ & $30 \% \mathrm{RH}$ \\
\hline AAS1 & $92.6 \%$ & $63.4 \%$ & $47.5 \%$ & $29.1 \%$ & $17.5 \%$ \\
AAS2 & $92.7 \%$ & $69.9 \%$ & $51.6 \%$ & $35.5 \%$ & $19.3 \%$ \\
AAS3 & $92.4 \%$ & $57.2 \%$ & $40.1 \%$ & $23.5 \%$ & $15.1 \%$ \\
AAS4 & $95.8 \%$ & $67.9 \%$ & $52.6 \%$ & $35.3 \%$ & $22.5 \%$ \\
OPC & $94.8 \%$ & $70.1 \%$ & $52.1 \%$ & $37.8 \%$ & $27.6 \%$ \\
\hline
\end{tabular}

a: It was measured at the end of 7-day moist curing

\subsection{Mercury intrusion porosimetry}

The MIP results for all five mixtures and the main pore structure characteristics are demonstrated in Figure 5 and Table 5, respectively. It should be noted that all five mortar mixtures had the same volume of liquid phase and the same porosity of $27.9 \%$ at the time of mixing (equivalent to a paste porosity of 56.5\%). It can be seen that AAS exhibits a comparable porosity but a significantly finer pore structure than OPC [12], with a considerable number of pores in the range of $10-100 \mathrm{~nm}$ in diameter. In addition, it is observed that slag activated by $\mathrm{NaOH}$ and water glass exhibits a finer pore structure than slag activated solely by $\mathrm{NaOH}$. The increased dosage (e.g. dissolved silicate content) also contributes to a finer pore structure.



(a)

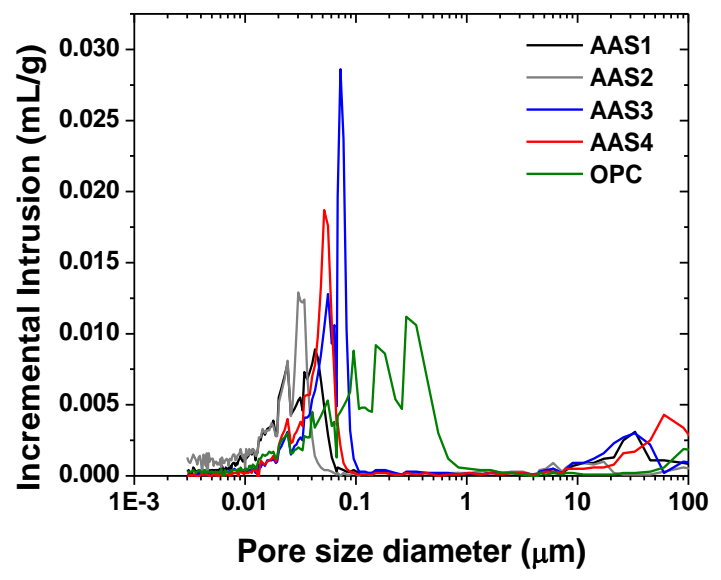

(b)

Figure 5 MIP results of all mixtures (a) cumulative pore volume; (b) incremental pore volume

Table 5 Pore structure characteristics of AAS and OPC obtained by MIP

\begin{tabular}{lccccc}
\hline Parameter & AAS1 & AAS2 & AAS3 & AAS4 & OPC \\
\hline $\mathrm{D}_{90}{ }^{\mathrm{a}}(\mathrm{nm})$ & 49.18 & 36.10 & 81.43 & 65.13 & 355.19 \\
$\mathrm{D}_{50}(\mathrm{~nm})$ & 25.68 & 21.60 & 60.65 & 46.28 & 76.03 \\
$\mathrm{D}_{10}(\mathrm{~nm})$ & 8.46 & 5.19 & 17.89 & 19.39 & 12.44 \\
\hline
\end{tabular}




\begin{tabular}{lccccc}
\hline Median pore diameter (Volume) $(\mathrm{nm})$ & 27.70 & 22.80 & 64.20 & 49.30 & 82.90 \\
Average pore diameter (4V/A) $(\mathrm{nm})$ & 19.00 & 13.10 & 37.20 & 35.90 & 33.30 \\
Porosity & $35.93 \%$ & $38.11 \%$ & $38.09 \%$ & $32.53 \%$ & $34.79 \%$ \\
\hline
\end{tabular}

a: $D_{x}$ means than $x \%$ of pores accessible through an entrance smaller than the particular pore size of $D_{x}$

\section{Discussion}

\subsection{Correlation between $R H$ and shrinkage}

The correlation between RH and drying shrinkage for all five mortar mixtures can be viewed in Figure 6. For the direct drying process, the OPC mixture shows a bi-linear relationship between RH and drying shrinkage, which was similarly measured and reported by other authors [23]. However, AAS mixtures show a parabolic relationship between ultimate shrinkage and RH in the case of direct drying. For example, AAS1 and AAS2 showed the highest shrinkage at 70\% RH, whilst AAS3 and AAS4 showed the highest shrinkage at 50\% RH.

However, the shrinkage behavior of AAS was found to differ significantly under the step-wise drying process, as compared to direct drying. For a step-wise drying, the largest drying shrinkage magnitudes were observed at the lowest RH. This may be attributed to the formation of irreversible shrinkage during the gradual drying process at high $\mathrm{RH}$ (i.e. creep effects). Furthermore, for step-wise drying, a broader range of sizes of pores can participate in the shrinkage (e.g. pore collapse) than that in direct drying at one particular RH. In addition, most of the shrinkage of AAS at high RH is basically permanent, as evidenced by the fact that step-wise drying shrinkage does not decrease when finally dried to $30 \% \mathrm{RH}$.

It should be noted that although the degree of hydration was not measured for AAS at the end of shrinkage measurements, previous work has shown that the degree of hydration at 7 days (all AAS were cured at moisture room for 7 days) can reach about $70 \%$ of its degree of hydration at 180 days [3]. Therefore, the significant shrinkage performance cannot be directly attributed to the difference in degree of hydration in AAS exposed to these two drying regimes. Nevertheless, the dramatic difference between shrinkage magnitudes at 30\% RH during step-wise and direct drying, indicates that the deformation occurred at high $\mathrm{RH}$ contributes significantly to the total shrinkage of AAS.

During the step-wise drying, each mixture lost slightly less mass compared to those dried directly at each RH (by comparing Figure 3 and Figure 4 (b)). This can be attributed to a slight increased hydration during the slower drying process, which promotes water binding in AAS. Additionally, direct drying can form a higher drying stress gradient over the width of samples [25], which may contribute to the formation of micro-cracks that facilitates the escape of evaporable moisture. 


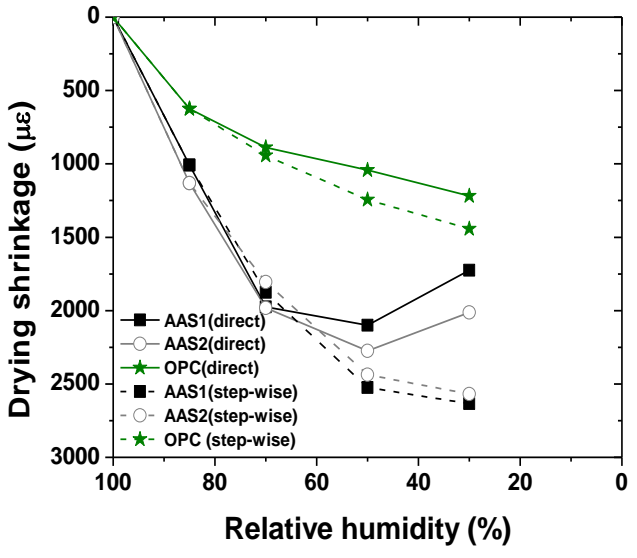

(a)

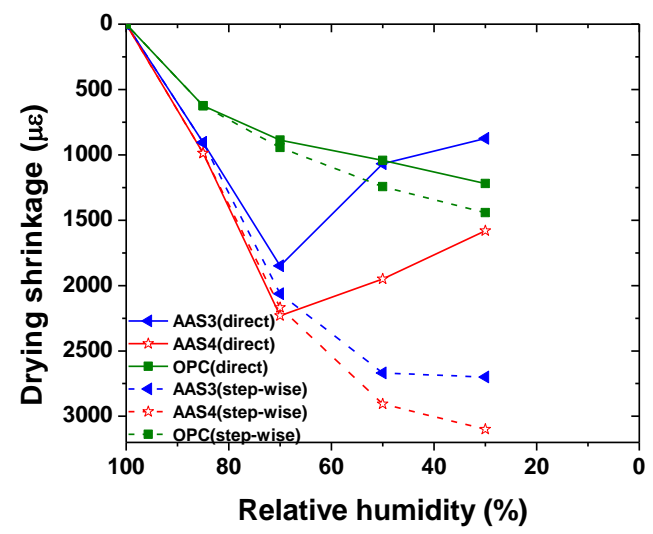

(b)

Figure 6 Ultimate drying shrinkage vs RH for all mortar mixtures (a) $\mathrm{NaOH}$-water glass activated slag (AAS1 and AAS2) (b) NaOH-activated slag (AAS3 and AAS4)

\subsection{Correlation between moisture loss and shrinkage}

The correlations between mass loss and drying shrinkage for all samples at various $\mathrm{RH}$ are shown in Figure 7. As expected, the drying shrinkage increases with the increase in moisture loss, but this correlation varies notably according to different drying rates. In addition, significant differences between AAS and OPC samples can be observed. OPC exhibits a strong correlation between moisture loss and shrinkage regardless of drying conditions, which agrees with previous research [22]. However, at any given level of moisture loss, all AAS mixtures tend to have higher shrinkage deformation when they are dried slowly (i.e. dried at higher RH). Therefore, it is concluded that for AAS systems, drying shrinkage is comparatively less correlated to the total amount of mass loss but tends to be sensitive to drying rate. In addition, at high RH (e.g. 70\% RH) conditions, AAS can continue to shrink although little moisture loss is observed, which indicates that the creep effects contribute to the shrinkage.
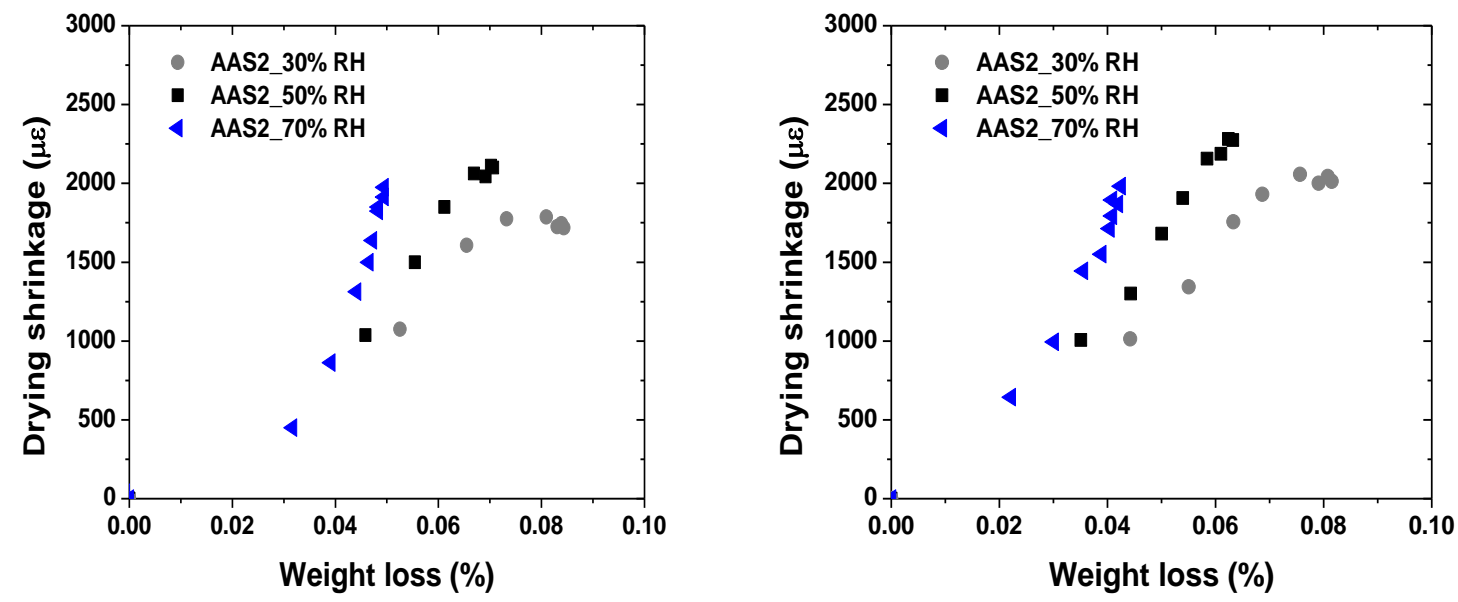
(a)

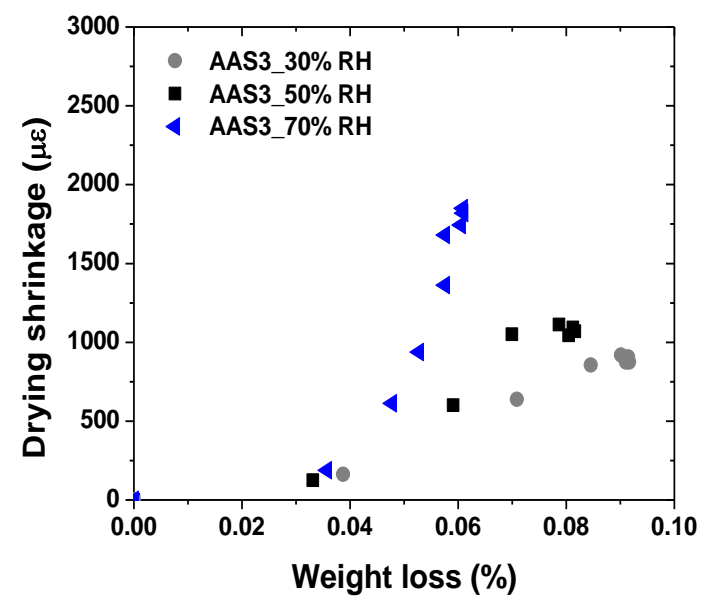

(c) (b)

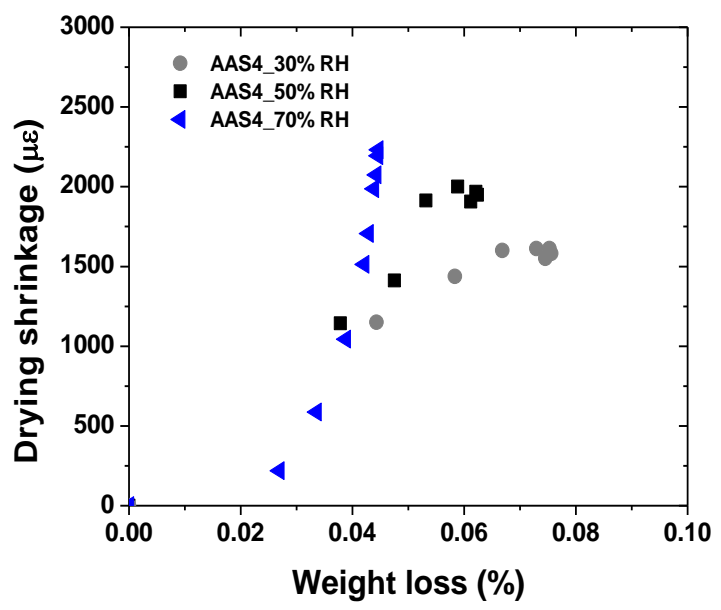

(d)



(e)

Figure 7 Correlation between mass loss percent and drying shrinkage dried at various $\mathrm{RH}$ (a) AAS1; (b) AAS2; (c) AAS3; (d) AAS4; (e) OPC

\subsection{Shrinkage kinetics}

The time-dependent shrinkage rates for all mixtures dried at various RH (both direct and stepwise drying) are shown in Figure 8. It can be seen that the shrinkage rate peak occurs at the time when samples are suddenly exposed to drying environments. Interestingly, OPC shows greater extent of shrinkage peaks at the time of drying than that of AAS for each $\mathrm{RH}$, but almost ceases to shrink later. However, although the initial shrinkage rates of AAS mixtures are slightly lower than that of OPC, their shrinkage rates last for a longer period of time. For example, the shrinkage rate of OPC approaches zero at 10 days after it is suddenly exposed to $70 \% \mathrm{RH}$, while the shrinkage rate of AAS can effectively last for about 40 days. It shows that this gradual increasing deformation contributes significantly to its ultimate shrinkage, which basically illustrates the visco-elastic/visco-plastic accumulation of deformation in AAS. It should be noted 
that this slower shrinkage kinetics in AAS is not mainly due to a slower moisture loss (as shown in Section 4.2), as AAS can continue shrinking although little mass change is observed. Therefore, it is reasonable to deduce that this slower shrinkage kinetics is likely associated with the high visco-elastic/visco-plastic compliances of AAS.

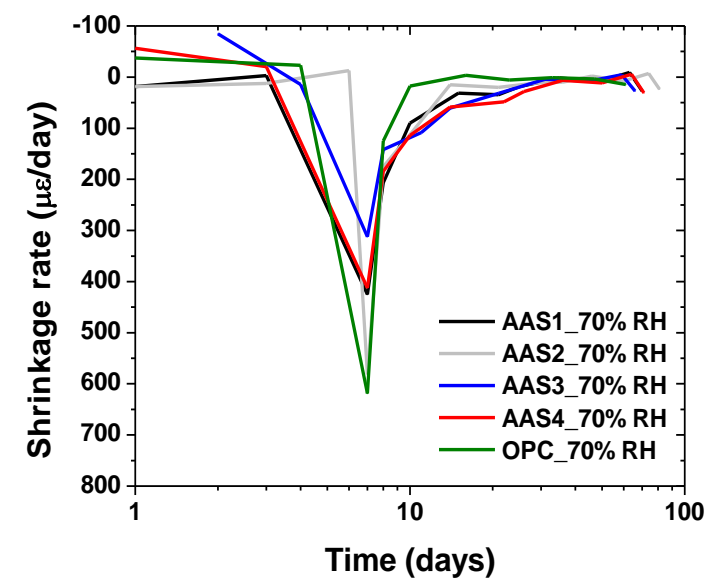

(a)

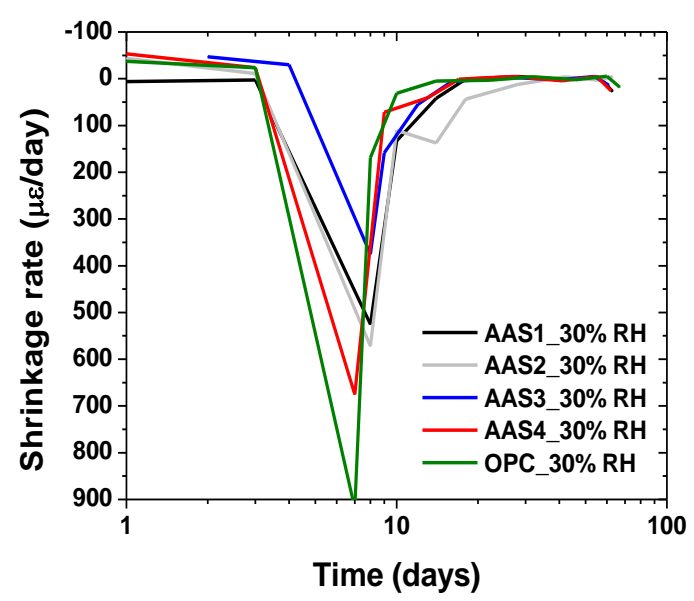

(c)

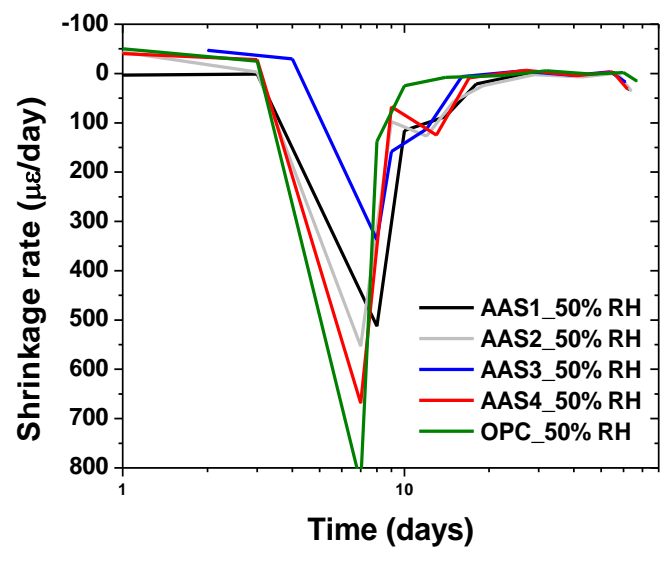

(b)

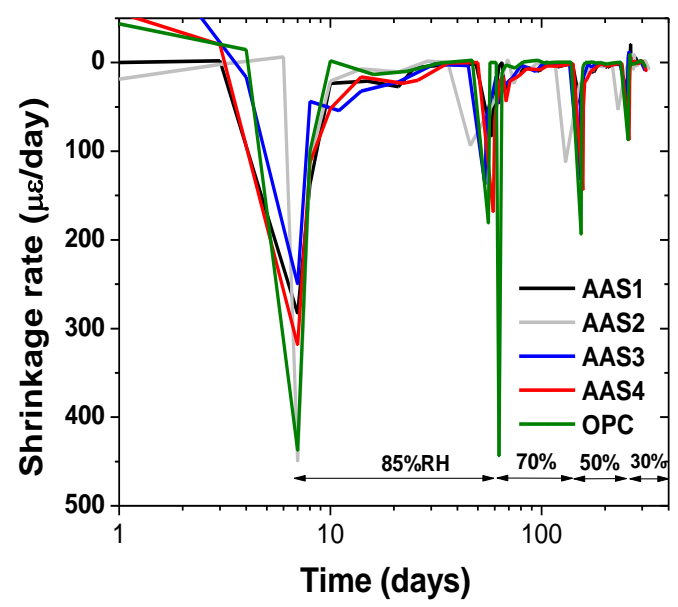

(d)

Figure 8 Shrinkage rate as a function of time at (a) direct 70\% RH drying, (b) direct 50\% RH drying, (c) direct 30\% RH drying (d) Step-wise drying from $85 \% \mathrm{RH}$ to $30 \% \mathrm{RH}$

\subsection{Correlation between shrinkage and degree of saturation}

Figure 9 shows the drying shrinkage of all mortar mixtures as a function of their degree of saturation. All AAS mortars show significant shrinkage up to and after the point of nearly constant degree of saturation being reached. This is strong evidence that these mixtures are experiencing additional deformations under a nearly constant shrinkage driving force (i.e. external moisture loss is nearly ceased). The OPC mortar shows very little additional shrinkage deformations after the degree of saturation has reached almost a constant value. AAS mixtures 
appear to show the highest amount of visco-elastic/visco-plastic deformation at higher RH and seem to stop shrinking after a certain $\mathrm{RH}(\sim 50 \% \mathrm{RH})$ or degree of saturation (approximately $40 \%)$, has been reached. It is likely that at low RH $(<50 \% \mathrm{RH})$, a change of shrinkage driving force occurs which eliminates this viscous deformation. Additionally, it has been shown that the deformation at high RH is almost permanent (Section 4.1), which implies that the drying shrinkage of AAS at high RH shows a notable viscous characteristic.

The drying shrinkage and degree of saturation in OPC shows strong linear trends regardless of the RH it was exposed to. However, this trend cannot be observed in AAS, which suggests that the degree of saturation is not the controlling factor in the drying shrinkage of AAS. It evidences that AAS is a visco-elastic/visco-plastic material with a high viscous compliance (i.e. low creep modulus), in comparison to OPC.

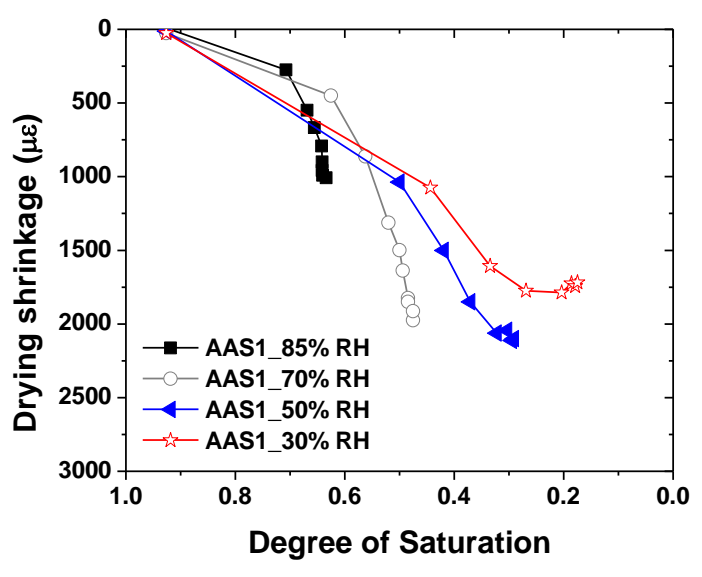

(a)

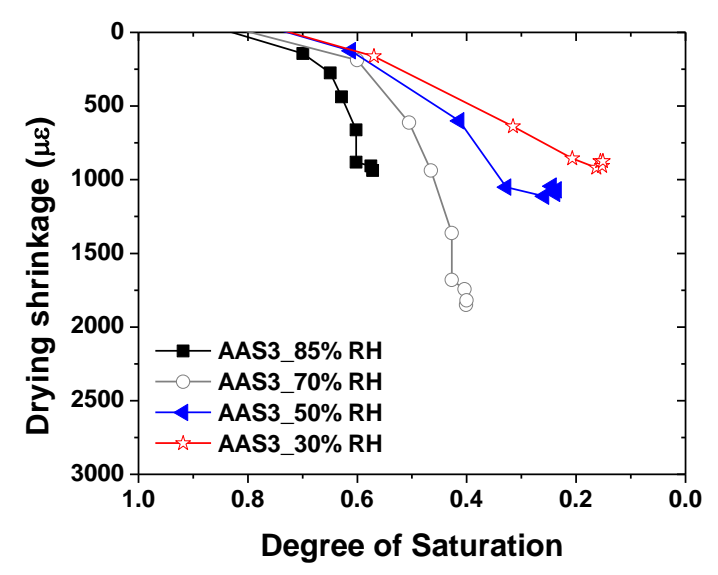

(c)

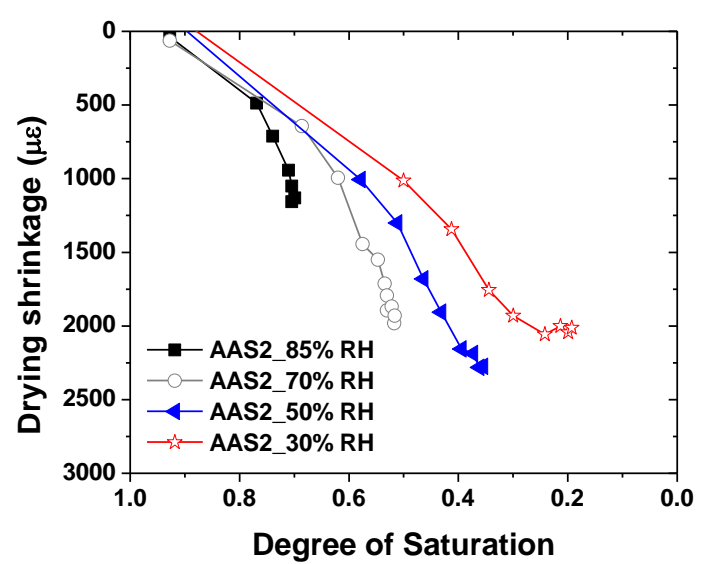

(b)

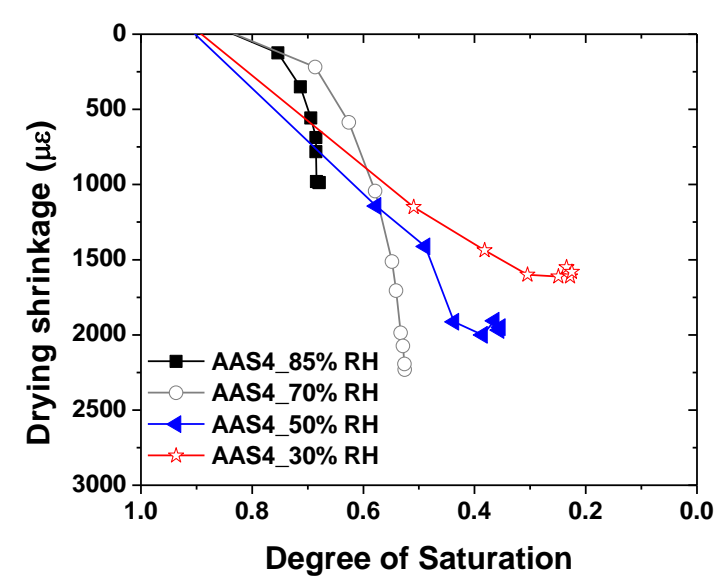

(d) 


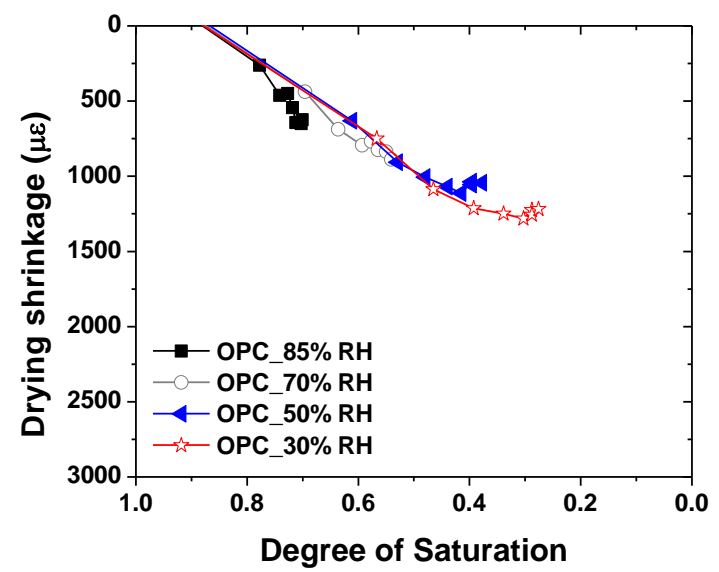

(e)

Figure 9 Correlation between shrinkage and degree of saturation for all mortar mixtures (a) AAS1; (b) AAS2; (c) AAS3; (d)AAS4; (e)OPC

\subsection{Mechanism of drying shrinkage}

\subsubsection{Shrinkage driving forces}

Due to the considerable visco-elastic/visco-plastic shrinkage characteristic in AAS, any isotropic elasticity-based shrinkage prediction models are therefore invalidated. Besides the intrinsic difference in material responses to loads, another primary concern is the origin of shrinkage driving force. At high $\mathrm{RH}(>\sim 40 \%-50 \% \mathrm{RH})$, capillary pressure is favored to be the dominating driving force in cementitious materials due to the presence of meniscus [26]. Most of the capillary pressure theory is based on the fundamental Kelvin-Laplace equation [27]:

$$
P_{c}=P_{g}-P_{l}=-\rho_{l} \frac{R T}{M_{l}} \ln \frac{R H}{a_{w}}=\frac{2 \gamma_{g l} \cdot \cos \theta_{g l}}{r-t}
$$

Where $P_{c}$ is the capillary pressure $[\mathrm{MPa}], P_{g}$ is the gas pressure $[\mathrm{MPa}], P_{l}$ is the liquid pressure [MPa], $\rho_{l}$ is density of liquid $[\mathrm{kg} / \mathrm{m} 3], M_{l}$ is molecular mass $[\mathrm{kg} / \mathrm{mol}]$ of liquid, $R=8.314[\mathrm{~J} /(\mathrm{mol}$ $\mathrm{K})]$ is the universal gas constant, $T$ is temperature $[\mathrm{K}], r$ is capillary radius $[\mathrm{m}]$ at the position of meniscus (as known as Kelvin radius), $a_{w}$ is the water activity, accounting for the presence of ions in pore solution, $\gamma_{\mathrm{gl}}=0.0728[\mathrm{~N} / \mathrm{m}]$ is surface tension between pore water and vapor due to the molecular interaction, $\theta_{g l}$ is the contact angle $\left[{ }^{\circ}\right]$ denoting the hydrophilicity of pore wall, $t$ is the thickness of adsorbed layer [m], which is function of RH [28].

According to Kelvin-Laplace equation, it can be seen that the determination of Kelvin radius is primarily based on the RH and pore solution properties, irrespective of the pore size [25]. In addition, at equilibrium condition, all pores whose radii are smaller than Kelvin radius are completely filled with water, whereas larger pores are partially saturated with a layer of adsorbed water with a thickness of $t[26,29]$. Considering that only the water-filled pores (radius larger than Kelvin radius) are able to form menisci and generate capillary pressure, the effective capillary stress at various RH can be approximated by multiplying the capillary pressure (based 
on Eq. (1)) with degree of saturation (see Figure 10 (a)), as shown in Figure 10 (b) [30, 31]. It shows that the effective capillary pressure is higher for OPC than AAS, which may question the higher driving force as a reason for the large shrinkage of AAS.

It should be noted that the degree of saturation is primarily dependent on the pore size distribution and properties of pore solution, according to Eq. (1). Furthermore, the water in small pores is more resistant to evaporation than larger pores at the same $\mathrm{RH}$. As a result, the material with a finer pore structure tends to have a higher degree of saturation [26]. Nevertheless, although MIP data indicates that AAS has an overall finer pore structure, the difference of pore size distribution between AAS and OPC below $5 \mathrm{~nm}$ in radius (for 70\% RH, the calculated Kelvin radius is about $4 \sim 5 \mathrm{~nm}$ ) is inconspicuous. On the other hand, the ionic concentration of pore solution in AAS is likely to be stronger than that of OPC due to its high alkalinity [32]. The surface tension of AAS pore solution, although has not been reported in the literature, tends to be similar or stronger than that of OPC, since the surface tension of electrolyte aqueous solutions tends to increase with decreasing water activity [33]. According to Eq. (1), both increased alkalinity and surface tension in pore solution can increase the Kelvin radius, as well as the degree of saturation, which contradicts to the measured data. Therefore, considering that AAS may have a refined pore structure than OPC even down to $5 \mathrm{~nm}$ as reflected in the MIP results, the study is likely to imply that the water may be more loosely bound in AAS.

According to the previous study on OPC, the shrinkage from $100 \%$ to $40 \% \sim 50 \% \mathrm{RH}$ is primarily responsible for the irreversible component due to structure alteration, while drying below $40 \%$ $\mathrm{RH}$ is almost recoverable [34, 35]. It indicates that the generation of capillary stress due to meniscus formation at high $\mathrm{RH}$ can contribute to the viscous deformation of AAS. While this viscous characteristic of AAS shrinkage almost vanishes when dried at $30 \% \mathrm{RH}$, implying another shrinkage driving force (probably densification of solid particles due to increased surface energy [26]) may dominate at low RH.

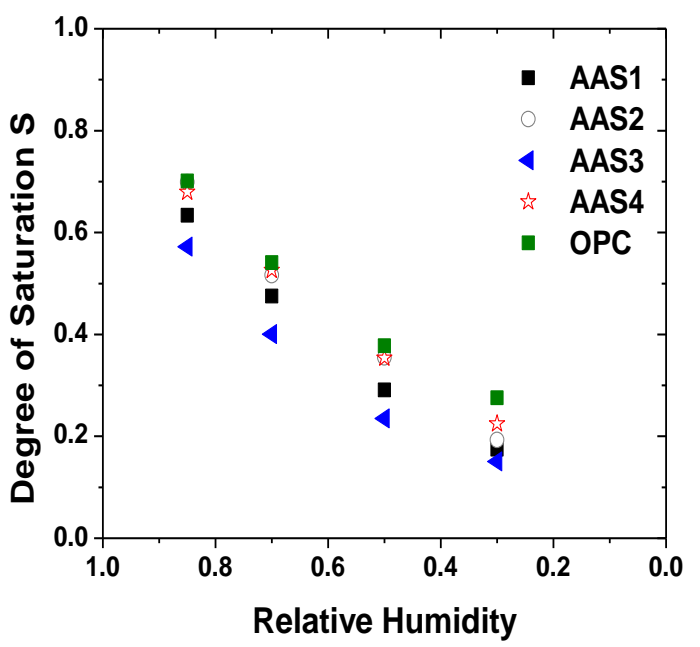

(a)

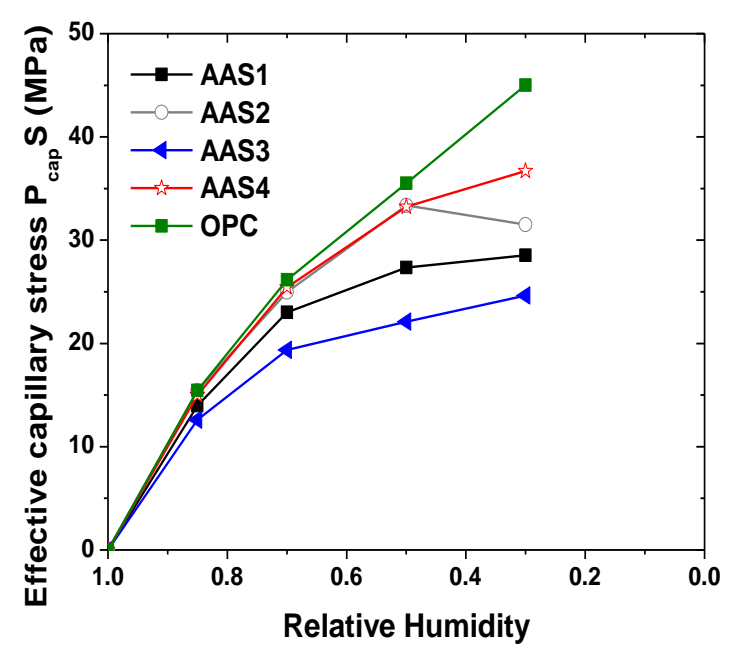

(b) 
Figure 10 (a) The degree of saturation in term of RH for all samples (b) The effective capillary pressure in term of degree of saturation for all samples. The capillary pressure was calculated using Kelvin equation with the adopted water activity values being one (Noted: at 30\%RH, the capillary pressure may not exist due to the unstable meniscus formation [36])

\subsubsection{Mechanical responses}

It has been shown that the large shrinkage of AAS is not likely due to a considerably increased driving force (effective capillary stress). Therefore, attention must be paid on the different shrinkage responses between AAS and OPC, upon similar magnitudes of stress. Considering the pronounced viscous shrinkage characteristics of AAS, the elastic modulus is insufficient to account for the deformation response. Nevertheless, a lower bulk modulus can still contribute to a larger deformation. As shown in Table 3, AAS3 and AAS4 mortars have more than 33\% lower bulk stiffness, which results in more than 1.5 times larger drying shrinkage based on isotropic linear elasticity calculations (if all other parameters remain the same). However, the stiffness values of AAS1 and AAS2 are similar to that of OPC; therefore, the elastic modulus is not responsible for the large shrinkage observed in these mixtures.

It is clear that the visco-elastic/visco-plastic deformation in AAS is associated with some sorts of time-dependent microstructure rearrangement and reorganization [37]. The intrinsic reasons responsible for this dramatic viscous shrinkage characteristic of AAS is likely to be associated with the unique nanostructure of $\mathrm{C}-\mathrm{A}-\mathrm{S}-\mathrm{H}$ with high alkali incorporation [38]. Comparable drying shrinkage magnitude and performance as that in AAS was observed in OPC system with significant alkali-enrichments [39].

\subsection{Influence of activator type/dosage on shrinkage}

The dissolved silicate from activator can notably affect the shrinkage characteristics and pore structure. As shown in Figure 6, the addition of dissolved silicate makes the highest shrinkage magnitude occurs at $50 \% \mathrm{RH}$ rather than $70 \% \mathrm{RH}$. It should be noted that the Kelvin radius at $50 \% \mathrm{RH}$ is about 3 4 $\mathrm{nm}$ smaller than that at $70 \% \mathrm{RH}$. It implies that the dissolved silicate increases the portion of smaller pores and enlarges the capillary forces at certain RH. Accordingly, the MIP data shows that dissolved silicate refines the pore structure. For $\mathrm{NaOH}-$ activated slag (AAS3 and AAS4), the increased dosage of $\mathrm{NaOH}$ can increase the magnitude of shrinkage, reduce the mass loss, and refine the pore structure. It is likely due to the increased degree of hydration [5]. Additionally, as shown in Section 4.5.2, the activator can affect the elastic modulus or other mechanical properties of AAS, which finally impact shrinkage.

\section{Conclusions}

In this paper, the shrinkage performance of AAS mortars under various drying conditions was investigated, contributing to a better understanding of the mechanisms for the large shrinkage in AAS. The following conclusions can be drawn based on this study:

(1) AAS has a higher mass loss, larger ultimate drying shrinkage magnitude, and slower shrinkage kinetics, in comparison to OPC at similar RH. 
(2) The ultimate shrinkage of AAS mixtures is not merely dependent on the RH or mass loss, but also the drying rate and drying history.

(3) Either with a similar amount of moisture loss or equilibrated at similar RH, AAS shrinks considerably more when dried gradually.

(4) The drying shrinkage of AAS shows a viscous characteristic at high $\mathrm{RH}$, indicating that AAS is a visco-elastic/visco-plastic material with low creep modulus.

(5) Dissolved silicate from activator affects the shrinkage characteristic of AAS by modifying the pore structure and mechanical properties.

(6) The large magnitude of shrinkage measured is likely not attributed to a higher driving force, but the more compliant mechanical response (i.e. visco-elastic/visco-plastic behaviors) of the solid skeleton in AAS

\section{Acknowledgements}

The authors gratefully acknowledge the financial support from the U.S. National Science Foundation (NSF) under Award CMMI \#1265789. Any opinions, findings and conclusions or recommendations expressed in this material are those of the authors and do not necessarily reflect the views of the NSF.

\section{References}

[1] R.J. Thomas, H. Ye, A. Radlińska, S. Peethamparan, Alkali-activated slag concrete: A closer look at sustainable alternatives to portland cement, Concrete International 38(1) (2016) 33-38.

[2] M. Juenger, F. Winnefeld, J. Provis, J. Ideker, Advances in alternative cementitious binders, Cement and Concrete Research 41(12) (2011) 1232-1243.

[3] M.B. Haha, G. Le Saout, F. Winnefeld, B. Lothenbach, Influence of activator type on hydration kinetics, hydrate assemblage and microstructural development of alkali activated blast-furnace slags, Cement and Concrete Research 41(3) (2011) 301-310.

[4] H. Ye, A. Radlińska, Fly ash-slag interaction during alkaline activation: Influence of activators on phase assemblage and microstructure formation, Construction and Building Materials 122 (2016) 594-606.

[5] H. Ye, A. Radlińska, Quantitative analysis of phase assemblage and chemical shrinkage of alkaliactivated slag, Journal of Advanced Concrete Technology 14 (2016) 245-260.

[6] S.-D. Wang, X.-C. Pu, K. Scrivener, P. Pratt, Alkali-activated slag cement and concrete: a review of properties and problems, Advances in cement research 7(27) (1995) 93-102.

[7] M. Jiang, X. Chen, F. Rajabipour, C.T. Hendrickson, Comparative life cycle assessment of conventional, glass powder, and alkali-activated slag concrete and mortar, Journal of Infrastructure Systems 20(4) (2014) 04014020.

[8] P. Duxson, J.L. Provis, G.C. Lukey, J.S. Van Deventer, The role of inorganic polymer technology in the development of 'green concrete', Cement and Concrete Research 37(12) (2007) 1590-1597.

[9] H. Ye, C. Cartwright, F. Rajabipour, A. Radlińska, Effect of drying rate on shrinkage of alkali-activated slag cements, 4th International Conference on the Durability of Concrete Structure (ICDCS), Purdue University, Indiana, USA, 2014, pp. 254-261.

[10] C. Cartwright, F. Rajabipour, A. Radlińska, Shrinkage characteristics of alkali-activated slag cements, Journal of Materials in Civil Engineering 27(7) (2015) B4014007

[11] T. Bakharev, J. Sanjayan, Y.-B. Cheng, Resistance of alkali-activated slag concrete to carbonation, Cement and Concrete Research 31(9) (2001) 1277-1283. 
[12] F. Collins, J. Sanjayan, Effect of pore size distribution on drying shrinking of alkali-activated slag concrete, Cement and Concrete Research 30(9) (2000) 1401-1406.

[13] A.A. Melo Neto, M.A. Cincotto, W. Repette, Drying and autogenous shrinkage of pastes and mortars with activated slag cement, Cement and Concrete Research 38(4) (2008) 565-574.

[14] A.A.M. Neto, M.A. Cincotto, W. Repette, Mechanical properties, drying and autogenous shrinkage of blast furnace slag activated with hydrated lime and gypsum, Cement and Concrete Composites 32(4) (2010) 312-318.

[15] C.D. Atiş, C. Bilim, Ö. Çelik, O. Karahan, Influence of activator on the strength and drying shrinkage of alkali-activated slag mortar, Construction and building materials 23(1) (2009) 548-555.

[16] T. Bakharev, J. Sanjayan, Y.-B. Cheng, Effect of elevated temperature curing on properties of alkaliactivated slag concrete, Cement and concrete research 29(10) (1999) 1619-1625.

[17] E. Douglas, A. Bilodeau, V. Malhotra, Properties and durability of alkali-activated slag concrete, $\mathrm{ACl}$ Materials Journal 89(5) (1992).

[18] F. Collins, J.G. Sanjayan, Strength and shrinkage properties of alkali-activated slag concrete containing porous coarse aggregate, Cement and Concrete Research 29(4) (1999) 607-610.

[19] A. Sakulich, D. Bentz, Mitigation of autogenous shrinkage in alkali activated slag mortars by internal curing, Materials and structures 46(8) (2013) 1355-1367.

[20] F. Puertas, M. Palacios, T. Vázquez, Carbonation process of alkali-activated slag mortars, Journal of Materials Science 41(10) (2006) 3071-3082.

[21] P. Lura, O.M. Jensen, K. van Breugel, Autogenous shrinkage in high-performance cement paste: an evaluation of basic mechanisms, Cement and Concrete Research 33(2) (2003) 223-232.

[22] W. Hansen, Drying shrinkage mechanisms in Portland cement paste, Journal of the American Ceramic society 70(5) (1987) 323-328.

[23] J. Weiss, P. Lura, F. Rajabipour, G. Sant, Performance of shrinkage-reducing admixtures at different humidities and at early ages, ACl Materials Journal 105(5) (2008).

[24] R. Thomas, S. Peethamparan, Elastic Modulus and Poisson's Ratio of Alkali-Activated Cement-Free Concrete, Transportation Research Board 94th Annual Meeting, 2015.

[25] G.W. Scherer, Theory of drying, Journal of the American Ceramic Society 73(1) (1990) 3-14.

[26] H. Ye, A. Radlińska, A review and comparative study of existing shrinkage prediction models for portland and non-portland cementitious materials Advances in Materials Science and Engineering 2016(2016) (2016) Article ID: 2418219.

[27] A.W. Adamson, A.P. Gast, Physical chemistry of surfaces, (1967).

[28] R. Badmann, N. Stockhausen, M.J. Setzer, The statistical thickness and the chemical potential of adsorbed water films, Journal of Colloid and Interface science 82(2) (1981) 534-542.

[29] A. Radlinska, F. Rajabipour, B. Bucher, R. Henkensiefken, G. Sant, J. Weiss, Shrinkage mitigation strategies in cementitious systems: A closer look at differences in sealed and unsealed behavior, Transportation Research Record: Journal of the Transportation Research Board 2070(1) (2008) 59-67.

[30] D.P. Bentz, O.M. Jensen, Mitigation strategies for autogenous shrinkage cracking, Cement and Concrete Composites 26(6) (2004) 677-685.

[31] D.P. Bentz, A review of early-age properties of cement-based materials, Cement and Concrete Research 38(2) (2008) 196-204.

[32] S. Song, H.M. Jennings, Pore solution chemistry of alkali-activated ground granulated blast-furnace slag, Cement and Concrete Research 29(2) (1999) 159-170.

[33] Z.-B. Li, Y.-G. Li, J.-F. Lu, Surface tension model for concentrated electrolyte aqueous solutions by the Pitzer equation, Industrial \& engineering chemistry research 38(3) (1999) 1133-1139.

[34] H.M. Jennings, Refinements to colloid model of CSH in cement: CM-II, Cement and Concrete Research 38(3) (2008) 275-289. 
[35] I. Maruyama, G. Igarashi, Y. Nishioka, Bimodal behavior of CSH interpreted from short-term length change and water vapor sorption isotherms of hardened cement paste, Cement and Concrete Research 73 (2015) 158-168.

[36] H.M. Jennings, A model for the microstructure of calcium silicate hydrate in cement paste, Cement and Concrete Research 30(1) (2000) 101-116.

[37] H. Ye, Creep Mechanisms of Calcium-Silicate-Hydrate: An Overview of Recent Advances and Challenges, International Journal of Concrete Structures and Materials 9(4) (2015) 453-462.

[38] H. Ye, A. Radlińska, Shrinkage mechanisms of alkali-activated slag, Cement and Concrete Research 88 (2016) 126-135.

[39] H. Ye, A. Radlińska, J. Neves, Drying and carbonation shrinkage of cement paste containing alkalis, Materials and Structures (under revision) (2017). 